\section{CIVILTEC}

Revista Técnico-Científica

de Engenharia Civil
Volume $2-$ n. $2-2021$

http://periodicos.unesc.net/engcivil

\title{
Estudo tipo-morfológico de praças no município de Forquilhinha/SC
}

Doi: http://dx.doi.org/10.18616/civiltec.v2i2.6842

Jorge Luiz Vieira ${ }^{1}$

Eduarda Andrade Campos ${ }^{2}$

\section{Introdução}

Dentro da categoria espaço público, as praças guardam um importante significado para as cidades. Desde o período clássico na Grécia (séc. V a.C.), onde surgiram como ágora, além de desempenharem papel funcional como ambiente de trocas diversas, as praças evocam um sentido de reunião, de contemplação e contato com elementos da natureza, e de referência urbana importante para os cidadãos. Mas, para que possam desempenhar seu genuíno papel, necessita-se muito mais do que as intenções de um bom projeto.

Diante disso, nota-se a necessidade de estudos sobre esse espaço e a complexidade das análises requeridas. Assim, este trabalho aborda a problemática das praças no município de Forquilhinha, situado na Região Carbonífera do estado de Santa Catarina, a 217 quilômetros da capital, Florianópolis. Forquilhinha faz parte da AMREC (Associação dos Municípios da Região Carbonífera).

A estrutura administrativa de Forquilhinha se caracteriza pela existência de distritos bem isolados e de uma extensa área rural (14.714 ha), quatro vezes maior que a área urbana (3.800 ha). O perímetro urbano concentra-se na região norte do município, entre os rios Mãe Luzia, Guaraparí e Sangão, este na divisa com Criciúma. Os bairros se desenvolvem de maneira espraiada e descontínua, com poucas áreas de maior urbanização.

À vista disso, esse trabalho tem como objetivo mapear, classificar e caracterizar os tipos de praças, urbanizadas ou não, existentes nos bairros da área urbana do município de Forquilhinha, por meio de estudos tipo-morfológicos. Para tanto, realizou-se levantamento e mapeamento das praças da cidade de Forquilhinha/SC para, em seguida, efetuar a classificação e a caracterização tipo-morfológica das praças selecionadas.

1 Professor Doutor, Departamento de Arquitetura e Urbanismo, Universidade do Extremo Sul Catarinense (UNESC), jov@unesc.net

2 Graduanda, Departamento de Arquitetura e Urbanismo, Universidade do Extremo Sul Catarinense (UNESC), eduardaacampos@unesc.net 


\section{CIVILTEC}

Revista Técnico-Científica

de Engenharia Civil

\section{Volume 2 - n. 2 - 2021}

http://periodicos.unesc.net/engcivil

\section{Metodologia}

A partir do embasamento teórico e do levantamento prévio das praças da área urbana do município de Forquilhinha, foram definidos os parâmetros que nortearam as análises, a classificação e a caracterização das mesmas, segundo elementos verificados a partir de imagens do Google Earth/Street View, visitas de campo e registros fotográficos.

Partiu-se da análise dos padrões de Alexander et al. (2013), extraídos do livro Uma Linguagem de padrões: A Pattern Language, que poderiam ser utilizados como norteadores dos estudos deste trabalho. A ideia fundamental da metodologia foi identificar um padrão principal relacionado aos espaços públicos e associá-lo a outros padrões afins, seguindo as relações possíveis sugeridas pelos autores, com o objetivo de estabelecer parâmetros de quantificação e qualificação dos espaços sob análise.

Posteriormente, foi analisado o trabalho desenvolvido pelos acadêmicos da disciplina de Estudos Urbanos (2018/2), no curso de Arquitetura e Urbanismo. A partir dos dados apresentados na disciplina, efetuou-se também a identificação dos equipamentos e praças dentro do perímetro urbano do município, por meio de um mapa da cidade, para posterior seleção daquelas que seriam objeto de análise.

\section{Resultados}

Com a identificação dos equipamentos e espaços públicos dentro do perímetro urbano do município, elaborou-se um mapa digital, na escala 1/12.500, no software AutoCad, contendo identificação, mapeamento e numeração dos equipamentos e espaços públicos. Com esse embasamento, foram selecionadas oito praças para análise, aplicando-se os parâmetros dos padrões de Alexander et al. (2013).

Após a análise dos padrões relacionados aos espaços públicos, estipulou-se como norteador o Padrão 61, intitulado "Praças Públicas Pequenas". Em seguida, foram mapeados os demais padrões que se relacionam direta ou indiretamente com o Padrão 61; foi desenvolvido então o "Diagrama dos Padrões Derivados do Padrão 61" (figura 1). 


\section{CIVILTEC}

Revista Técnico-Científica

de Engenharia Civil
Volume $2-$ n. $2-2021$

http://periodicos.unesc.net/engcivil

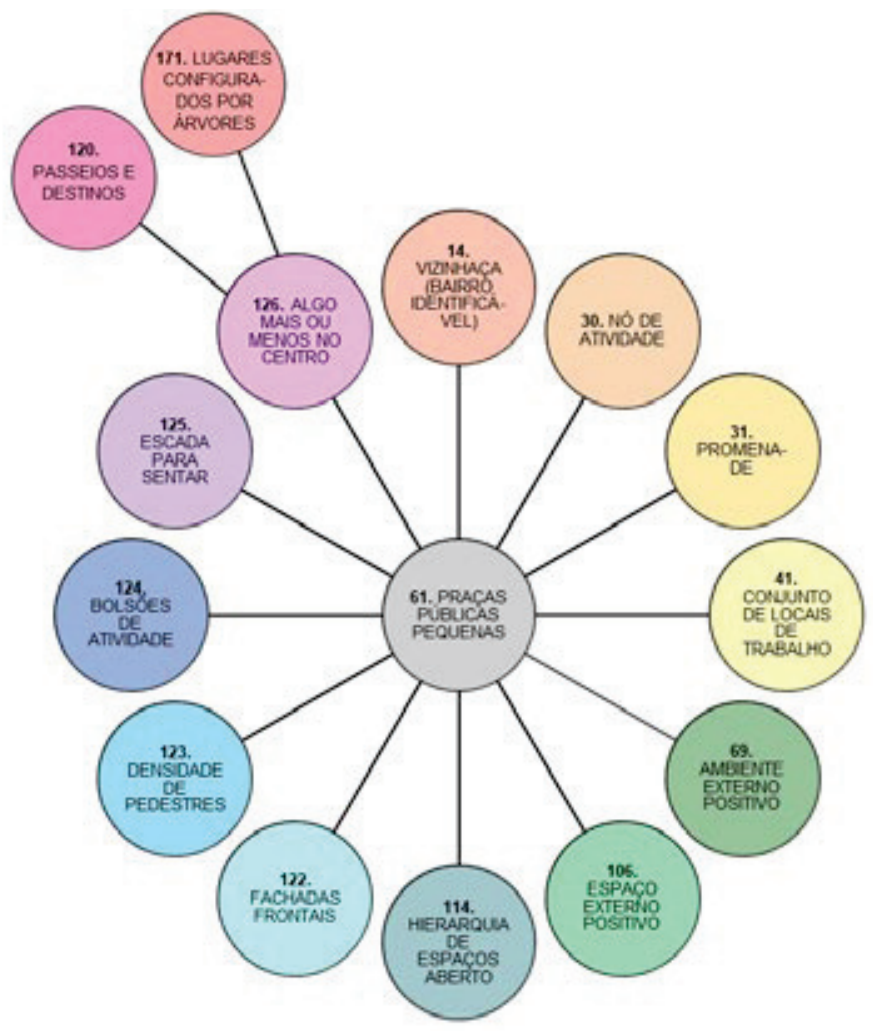

Figura 1. Diagrama dos "Padrões Derivados do Padrão 61". (Fonte: elaboração própria, 2020)

Com base nisso, possibilitou-se a elaboração do "Quadro de variáveis dos padrões relacionados ao Padrão 61 - Praças Públicas Pequenas". Nesse quadro, são abordadas as variáveis quantitativas e qualitativas estabelecidas por Alexander et al. (2013) em cada padrão, bem como realizada a pesquisa de referenciais que respondem aos parâmetros e que auxiliaram nas análises de campo.

Somente após a elaboração desses materiais, foi possível realizar a efetiva análise individual das oito praças: 1. Praça do bairro Santa Ana, 2. Praça Linear do bairro Santa Ana, 3. Praça do Imigrante Alemão do bairro Centro, 4. Praça do bairro Vila Lourdes, 5. Praça do bairro Nova York, 6. Praça Mário Tiscoski do bairro Ouro Negro, 7. Praça do bairro Santa Cruz e 8. Praça do bairro Cidade Alta (figura 2). Para tanto, foram produzidos quadros analíticos. Cada um com os seguintes dados: diagnósticos gráficos; planta de localização da praça selecionada no perímetro urbano de Forquilhinha; planta de localização da praça selecionada no bairro; mapeamento dos equipamentos e delimitação dos raios determinantes para os parâmetros; figura pontuando os cheios e vazios do entorno da praça; e diagnósticos, contemplando as análises de cada parâmetro de quantificação e qualificação dos padrões. Para agregar mais informações, foram anexados registros fotográficos realizados nas visitas a campo. 


\section{CIVILTEC}

Revista Técnico-Cientifica

de Engenharia Civil

\section{Volume 2 - n. 2 - 2021}

http://periodicos.unesc.net/engcivil
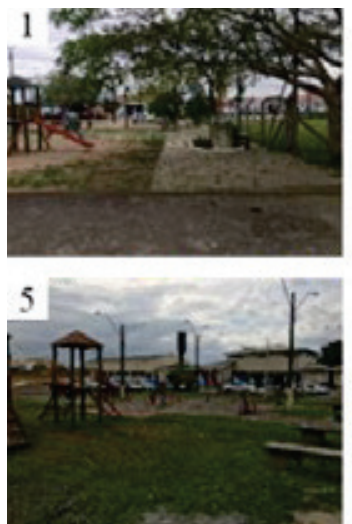
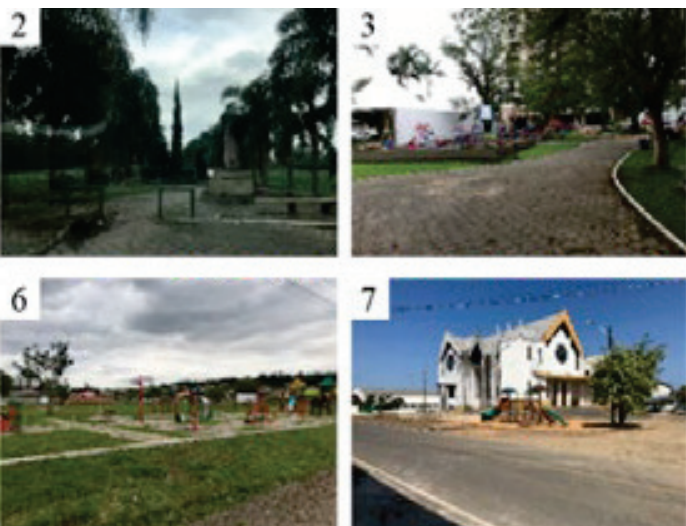

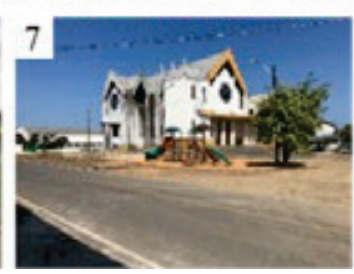

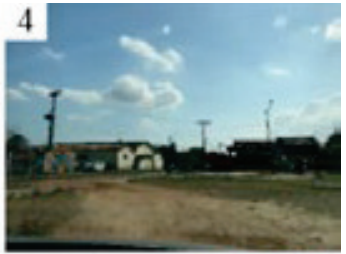

8

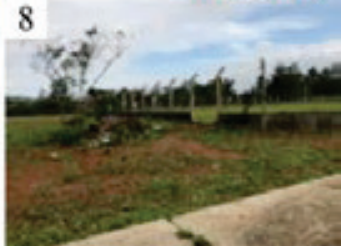

Figura 2. Registros Fotográficos de cada praça selecionada para análise. (Fonte: elaboração própria, 2020)

Ao término das análises individuais, elaborou-se o "Quadro Comparativo das Variáveis Quantitativas" e o "Quadro Comparativo das Variáveis Qualitativas", que completaram as análises das oito praças sobre os quinze parâmetros predefinidos, o que permitiu a produção de uma descrição das principais características de cada uma delas quanto à sua condição de atratividade e vitalidade urbana, propiciando a classificação tipológica, realizada, ao final, por meio de breve descrição das diferenças quantitativas e qualitativas de cada praça.

\section{Consideraç̃ões Finais}

Os produtos das análises resultaram na conclusão de que, de forma geral, as praças selecionadas apresentam um baixo nível de organicidade e estruturação a partir dos parâmetros estudados, além de um baixo grau de urbanização. Diante disso, entende-se que a maioria dos espaços públicos estudados não possui apropriação da vizinhança do entorno, acarretando ambientes de pouca vivacidade e, portanto, praticamente ausentes de urbanidade.

Como desfecho, pretende-se com o trabalho chamar a atenção acerca do sentido do espaço público na cidade contemporânea e suas implicações na sociedade. Embora a importância das praças seja vital para a cidadania, o seu potencial como gerador de urbanidade depende de uma série de fatores que devem ser considerados no processo de projeto.

A interpretação e a combinação dos padrões de Alexander et al. (2013) permitiram inferir uma análise relativamente adequada e que possibilitaram classificar e diferenciar quantitativa e qualitativamente cada praça selecionada. No entanto, observou-se que os resultados foram mais claros e objetivos no que se refere aos dados de quantificação. Já os dados de qualificação, que são os que reforçam os graus de apropriação no tempo, ficaram reduzidos a poucas visitas de observação, devido à limitação do tempo de pesquisa. 


\section{CIVILTEC}

Revista Técnico-Científica de Engenharia Civil
Volume $2-$ n. 2 - 2021

http://periodicos.unesc.net/engcivil

Porém, de toda forma, a pesquisa atingiu seu principal objetivo que era, a partir da combinação de padrões espaciais definidos por Alexander et al., classificar e caracterizar cada praça selecionada.

Palavras-chave: Tipologias. Praças. Espaços Públicos. Morfologia Urbana. Forquilhinha.

Fonte de financiamento: Projeto de Iniciação Científica (PIC 170) - UNESC, Edital 01/2019.

\section{Referências}

ALEXANDER, Christopher et al. Uma linguagem de padrões: A Pattern Language. Porto Alegre: Bookman, 2013.

ARGAN, Giulio Carlo. Projeto e destino. Tradução de Nanos Bagno. 1. ed. São Paulo: Ática, 2000.

CARBONERAYOKOO, Sandra; CHIES, Cláudia. O papel das praças públicas: estudo de caso da praça raposo tavares na cidade de Maringá. 2009. Disponível em: <http://www.fecilcam.br/nupem/ anais_iv_epct/PDF/ciencias_exatas/12_YOKOO_CHIES.pdf>. Acesso em: 11 mar. 2019.

IBGE - Instituto Brasileiro de Geografia e estatística. Forquilhinha, Santa Catarina. 2010. Disponível em: <https://cidades.ibge.gov.br/brasil/sc/forquilhinha/panorama>. Acesso em: 23 jun. 2019.

LAMAS, José Maria Ressano Garcia. Morfologia Urbana e Desenho da Cidade. 2. ed. Lisboa: Fundação Calouste Gulbenkian, 2000.

MASCARÓ, Lucia A. Raffo. Ambiência urbana: Urban environment. 2. ed. Porto Alegre: +4, 2004. $197 \mathrm{p}$.

PANERAI, Philippe et al. Elementos de análisis urbano. Madrid: Instituto de Estudios de Administración Local - Colección “Nuevo Urbanismo”, 1983.

PROJECT FOR PUBLIC SPACES. Como avaliar a qualidade de um espaço público? Tradução de Vinicius Libardoni. Archdaily, 16 abr. 2019. Disponível em: <https://www.archdaily.com.br/ br/915132/como-avaliar-a-qualidade-de-um-espaco-publico>. Acesso em: 3 maio 2019.

VIEIRA, Ivanete de Mesquita Orsi. Configuração e apropriação do espaço público. Estudo de duas praças em Criciúma/SC. Dissertação (Mestrado em Arquiterura e Urbanismo) - Universidade Federal de Santa Catarina. Florianópolis, 2010.

VIEIRA, Jorge Luiz. Habitação coletiva econômica, Urbanidade e Habitabilidade: estudo tipológico em Porto Alegre/RS e Montevidéu/Uruguai. Tese (Doutorado em Arquitetura) - Universidade Federal do Rio Grande do Sul, Faculdade de Arquitetura, Programa de Pós-Graduação em Arquitetura. Porto Alegre-RS, 2017.

UNESC. Curso de Arquitetura e Urbanismo. Matriz 03. Disciplina de Estudos Urbanos, 2018/2. 7ạ fase. 